\title{
Retromolar Intubation in Maxillofacial Trauma Patients
}

\author{
${ }^{1}$ Suman Arora, ${ }^{2}$ Neerja Bhardwaj, ${ }^{3}$ Vidya Rattan
}

\begin{abstract}
Awareness of availability of retromolar route for intubation amongst anesthetists and surgeons for management of maxillofacial trauma seems to be low. In majority of centers submental route for intubation is a popular technique. The purpose of this article is to increase awareness regarding availability of retromolar route for intubation among the clinicians who take care of patients with maxillofacial trauma.
\end{abstract}

Keywords: Maxillofacial trauma, Airway management, Retromolar intubation.

How to cite this article: Arora S, Bhardwaj N, Rattan V. Retromolar Intubation in Maxillofacial Trauma Patients. J Postgrad Med Edu Res 2014;48(2):109-110.

Source of support: Nil

Conflict of interest: None

\section{INTRODUCTION}

Airway management during maxillofacial trauma surgery precludes the use of conventional oral tracheal intubation as it does not allow intraoperative assessment of the occlusion and maxillomandibular wiring which is often required for exact reduction of facial fractures. Nasotracheal intubation an alternative way of securing the airway is also not available when simultaneous access to nose and oral cavity is required in certain cases. Moreover, nasal intubation may be contraindicated in patients with basal skull fracture. Other routes for gaining access to airway are submental route and tracheostomy, which are invasive procedures and may be associated with significant morbidity. ${ }^{1}$

Retromolar intubation has been accepted as a satisfactory noninvasive alternative technique for maintaining the airway in adults as well as pediatric patients with maxillofacial trauma undergoing maxillomandibular fixation without obscuring the surgical field or compromising the safety and patency of the airway. ${ }^{2-6}$ Retromolar intubation was first

\footnotetext{
${ }^{1,3}$ Additional Professor, ${ }^{2}$ Professor

1,2Department of Anesthesia and Intensive Care, Postgraduate Institute of Medical Education and Research, Chandigarh, India

${ }^{3}$ Unit of Oral and Maxillofacial Surgery, Oral Health Sciences Centre, Postgraduate Institute of Medical Education and Research, Chandigarh, India
}

Corresponding Author: Suman Arora, Additional Professor Department of Anesthesia and Intensive care, Postgraduate Institute of Medical Education and Research, Chandigarh, India Phone: 9914209528, e-mail: drsumanarora@hotmail.com described by Martinez et al in complex craniomaxillofacial surgeries in which ostectomy was done at the ascending ramus of mandible to create space for endotracheal tube. ${ }^{7}$

In our experience with adults, we have never felt the need to do ostectomy at the anterior border of ramus of mandible for creating space for endotracheal tube. We have proven that there is enough space in children for endotracheal intubation through retromolar route. ${ }^{2}$ In adults where third molars are erupted and space is inadequate, these can extracted by the treating oral and maxillofacial surgeon to make space for endotracheal tube. In majority of cases third molars are malpositioned, impacted and are cause of periodontal disease and dental caries. Therefore, these are otherwise indicated for extraction in majority of population and do not require replacement. Awareness of availability of retromolar route for intubation among anesthetists and surgeons seems to be low. In majority of centers submental route for intubation is a popular technique. The purpose of this article is to increase awareness regarding availability of retromolar route for intubation among the clinicians who take care of patients with maxillofacial trauma.

Retromolar space lies at the rear of the mandible between the back of the last erupted molar and the anterior edge of the ascending ramus of mandible. It is bounded superiorly by the maxillary tuberosity and the retrotuberosity area, inferiorly by the retromolar trigone area, anteriorly by the last erupted molar teeth, posteriorly by the anterior border of ascending ramus of the mandible, medially by the lateral surfaces of the tuberosity, the last erupted molars and the oral cavity and laterally by the medial surface of ascending ramus and the buccal vestibule. ${ }^{2}$

The primary requisite for successful placement of tracheal tube in retromolar area is the existance of adequate space in this area. Adequacy of the space can be judged by placing a gloved index finger in the retromolar space and asking the patient to close slowly on the finger. No compression on the finger suggests enough retromolar space. Alternatively an orthopantograph may be helpful in evaluating the adequacy of the retromolar space, but it provides only a two dimensional picture and this may not be adequate (Fig. 1). Definitive assessment of the space is possible only under general anesthesia. Once the patient is intubated orally, airway pressure and arterial oxygen saturation $\left(\mathrm{SpO}_{2}\right)$ is noted. The tube is then repositioned behind the upper last molar in the retromolar space of non-operative side. The 
maximum intercuspation of teeth is attempted by closing the mandible, and the ability to achieve centric occlusion is determined (Fig. 2). At the same time, any increase in airway resistance or decrease in $\mathrm{SpO}_{2}$ is noted, no change in parameters indicates adequate space, and the tracheal tube is then secured in the retromolar space by transdental wiring around the molar or premolar teeth. Any increase in

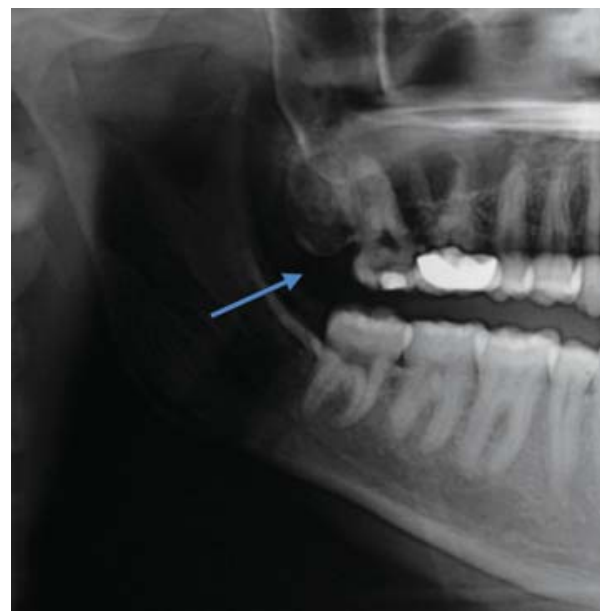

Fig. 1: Orthopantomograph showing retromolar space (arrow)

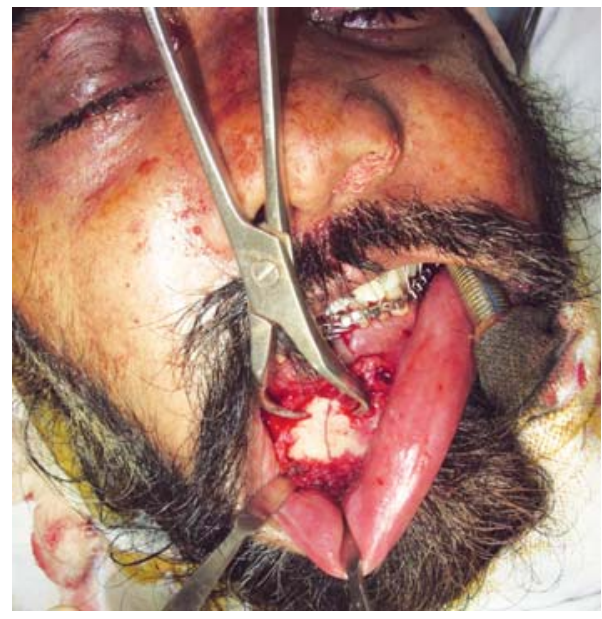

Fig. 2: Intraoperative photograph in a case of fracture mandible and nasoethmoidal bones. Flexometallic endotracheal tube is exiting through retromolar space. Intermaxillary fixation in place aiding in fracture reduction. Tube has been fixed to teeth with help of wire airway pressure or decrease in $\mathrm{SpO}_{2}$ indicates inadequate retromolar space. The retromolar space can be increased by extracting erupted or impacted mandibular or maxillary third molar. ${ }^{8}$ In our experience, extraction of third molars provides sufficient space for endotracheal tube placement and there is no need to remove bone from anterior ascending ramus.

Retromolar intubation avoids the use of submental intubation and tracheostomy which is invasive, time consuming and associated with complications and surgical morbidity. The main disadvantage of this technique may be that the tracheal tube can take up the space for intraoral access to mandibular angle fracture on the same side. This can be overcome by shifting of the tube to contralateral side, which is quick, easy and safe.

We use this technique routinely at our institute and we have rarely felt the need to do submental intubation or tracheostomy for the sole purpose of gaining access to airway for anesthesia purpose in maxillofacial trauma patients.

\section{REFERENCES}

1. Lee SS, Huang HS, Wu SH, Sun IF, Chu KS, Lai CS, Chen YL. A review of intraoperative airway management for midface facial bone fracture patients. Ann Plast Surg 2009;63:162-166.

2. Arora S, Rattan V, Bhardwaj N. An evaluation of the retromolar space for oral tracheal tube placement for maxillofacial surgery in children. Anesth Analg 2006;103:1122-1125.

3. Dutta A, Kumar V, Saha SS, Sood J, Khazanchi RK. Retromolar tracheal tube positioning for patients undergoing faciomaxillary surgery. Can J Anaesth 2005;52:341.

4. Bhardwaj N, Arora S, Sharma RK. Retromolar intubation in the management of facial trauma. J Anaesth Clin Pharm 2006;22: 91-92.

5. Habib A, Zanaty OM. Use of retromolar intubation in paediatric maxillofacial trauma. Br J Anaesth 2012;109:650-651.

6. Jain G, Dhama SS, Singh DK. Role of retromolar intubation for airway management in trauma. Adv Trop Med Pub Health Int 2011;1: 21-32.

7. Martinez-Lage JL, Eslava JM, Cebrecos AI, Marcos O. Retromolar intubation. J Oral Maxillofac Surg 1998;56:302-305.

8. Gibbons AJ, Hope DA, Silvester KC. Oral endotracheal intubation in the management of midfacial fractures. Br J Oral Maxillofac Surg 2003;41:259-260. 